\title{
Efecto de dos medios de fertilización en el desarrollo in vitro de embriones bovinos criollos
}

\author{
Effect of two fertilization medium on the in vitro development \\ of Creole bovine embryos
}

\author{
José Goicochea Vargas', Wilson Rondón Jorge ${ }^{1}$, Fidel Acosta Pachorro ${ }^{1}$, Yusep \\ Gómez Marín', Magaly Montalvo Martin', Max Salvatierra Alor², Jéssica Martel \\ Falcón $^{1}$, Oscar Ballarte Zevallos', Julio Díaz Zegarra', Marcelo Ratto Fuster ${ }^{3}$
}

\section{Resumen}

El objetivo del presente estudio fue evaluar la tasa de producción de embriones in vitro hasta el estadio de blastocisto con dos medios de fertilización: FERT-TALP y TCM199 modificado, cultivado en el medio BOEC, a partir de ovocitos recolectados por aspiración folicular de ovarios de vacas criollas obtenidos del matadero. Se recolectaron 281 ovocitos, 179 para el medio FERT-TALP y 144 para TCM-199 modificado. Los ovocitos fueron sometidos al proceso de maduración, fecundación y cultivo embrionario in vitro. Se obtuvo una tasa de clivaje de ovocitos de $25.8 \%$ en FERT-TALP y $2.4 \%$ en TCM-199 modificado a las 18 horas pos-fertilización. Asimismo, a las $48 \mathrm{~h}$ se obtuvo $87.7 \%$ de

\footnotetext{
${ }^{1}$ Laboratorio de Cirugía y Biotecnología Reproductiva, Facultad de Medicina Veterinaria y Zootecnia, Universidad Nacional Hermilio Valdizan (UNHEVAL), Huánuco, Perú

${ }^{2}$ Laboratorio de Biotecnología Molecular, Universidad Nacional Hermilio Valdizan (UNHEVAL), Huánuco, Perú

${ }^{3}$ Instituto de Ciencia Animal, Universidad Austral de Chile, Valdivia, Chile

${ }^{4}$ E-mail: goivar22@hotmail.com
}

Financiamiento: Fondos Concursables de la Universidad Nacional Hermilio Valdizan. Resolución rectoral $N^{\circ}$ 1167-2019-UNHEVAL

Recibido: 31 de agosto de 2020

Aceptado para publicación: 10 de marzo de 2021

Publicado: 27 de octubre de 2021

CLos autores. Este artículo es publicado por la Rev Inv Vet Perú de la Facultad de Medicina Veterinaria, Universidad Nacional Mayor de San Marcos. Este es un artículo de acceso abierto, distribuido bajo los términos de la licencia Creative Commons Atribución 4.0 Internacional (CC BY 4.0) [https:// creativecommons.org/licenses/by/4.0/deed.es] que permite el uso, distribución y reproducción en cualquier medio, siempre que la obra original sea debidamente citada de su fuente original 
clivaje total en FER-TALP y $40.5 \%$ en TCM-199 modificado, cuyo porcentaje de embriones con 4 a 8 células fue de 64.5 y $26.2 \%$ respectivamente. En la fase de mórula y blastocisto se alcanzó una tasa de 10.3 y $3.9 \%$ en FERT-TALP, respectivamente, mientras que ninguno se logró con el medio TCM-199 modificado.

Palabras claves: FERT-TALP, TCM-199, embriones, in vitro, bovinos criollos

\title{
Abstract
}

\begin{abstract}
The objective of this study was to evaluate the in vitro embryo production rate up to the blastocyst stage with two fertilization media: FERT-TALP and modified TCM-199, grown in BOEC medium, from oocytes collected by aspiration of follicular ovaries of creole cows obtained from the slaughterhouse. In total, 281 oocytes were collected, 179 for FERT-TALP medium and 144 for modified TCM-199. The oocytes were subjected to the process of maturation, fertilization and embryo culture in vitro. An oocyte cleavage rate of $25.8 \%$ was obtained in FERT-TALP and 2.4\% in modified TCM-199 at 18 hours post-fertilization. Likewise, at $48 \mathrm{~h}, 87.7 \%$ of total cleavage was obtained in FER-TALP and $40.5 \%$ in modified TCM-199, whose percentage of embryos with 4 to 8 cells was 64.5 and $26.2 \%$, respectively. In the morula and blastocyst phase, a rate of 10.3 and $3.9 \%$ was achieved in FERT-TALP, respectively, while none wwere achieved with the modified TCM-199 medium.
\end{abstract}

Key words: FERT-TALP, TCM-199, in vitro, embryos, native cattle

\section{INTRODUCCIÓN}

La maduración y fertilización in vitro de ovocitos y el cultivo y trasferencia embrionaria tiene por finalidad lograr crías de alto merito genético, mejorando así los índices productivos y reproductivos. No obstante, el desarrollo embrionario natural presenta una compleja serie de procesos fisiológicos que son difíciles de replicar in vitro, condicionando de manera significativa la producción de embriones, de allí que solo se logra hasta un 30\% para el estadio de blastocisto (López et al., 2007; Ahuja et al., 2009), estadio en que se define la calidad y mayor porcentaje de pérdidas embrionarias (Enrigh et al., 2000; Rizos et al., 2002; Galli et al., 2003, Lonergan et al., 2004).
Fisiológicamente, la fecundación del ovocito se realiza en la región ampular del oviducto, quien proporciona el ambiente biofísico adecuado y los elementos orgánicos e inorgánicos necesarios para la sobrevida y desarrollo. En cambio, la fecundación in vitro (FIV) emplea medios de cultivos enriquecidos, que proveen un ambiente simulado al ovocito maduro y a los espermatozoides, donde pueda darse el proceso de la penetración espermática (Adeoya-Osiguwa y Fraser, 2002; Fraser y Adeoya-Osiguwa, 2001; Gordon, 2003). En consecuencia, la formulación de medios para FIV debe incluir componentes que promuevan la motilidad y capacitación espermática, la fusión de los gametos y el inicio del desarrollo embrionario. Muchos de estos medios para fertilización, como el FERT-TALP, son medios simples, que 
priorizan condiciones favorables para los espermatozoides, sin considerar los requerimientos para los ovocitos (Nedambale et al., 2006).

A diferencia de los medios tradicionales de fertilización que contienen pocos componentes (FERT- TALP), los medios de maduración como TCM-199, son más apropiados para el desarrollo de ovocitos y embriones (Nedambale et al., 2006). El TCM-199 posee en su composición antioxidantes como glutatión y ácido ascórbico, que juegan un rol importante durante la fecundación, protegiendo al ovocito y espermatozoides del efecto de los radicales libres (Bilodeau et al., 2001). Los radicales libres, como el peróxido de hidrógeno, disminuyen la motilidad de los espermatozoides bovinos (Aitken et al., 1989) y la capacidad espermática para penetrar el ovocito (Aitken et al., 1989; Irvine, 1996). Por ello, en el presente estudio se utilizó el medio de maduración TCM-199 modificado (con adición de gentamicina, piruvato de sodio $0.2 \mathrm{mM}$ y BSA Faty free) en comparación con el medio FERT-TALP en la etapa de fertilización, cultivado en el medio BOEC (células epiteliales oviductal bovino) (Xu et al., 1992) a partir de ovocitos recolectados por aspiración folicular.

\section{Materiales y MéTodos}

El trabajo experimental se realizó en el laboratorio de Cirugía y Biotecnología Reproductiva de la Facultad de Medicina Veterinaria y Zootecnia de la Universidad Nacional Hermilio Valdizán, en Huánuco, Perú.

\section{Recolección de Ovocitos}

Se recolectaron ovarios, cuernos uterinos y oviductos de vacas criollas beneficiadas en el camal municipal de Huánuco. Los ovarios se colocaron en termos con $1 \mathrm{~L}$ de solución fisiológica con albúmina sérica bovina (BSA) y antibiótico (Bovi Flush-Minitube), a una temperatura de $38.5^{\circ} \mathrm{C}$ y llevados al laboratorio en un tiempo no mayor a las 4 horas. Los ovarios en el laboratorio fueron lavados empleando la misma solución y mantenidos en baño maría a la misma temperatura. Los ovocitos se obtuvieron por aspiración de folículos de 2-6 mm de diámetro, mediante una jeringa de $10 \mathrm{ml}$ con aguja 21G. El contenido de la aspiración se recuperó en tubos Falcon de $50 \mathrm{ml}$ y se dejó decantar a $38.5^{\circ} \mathrm{C}$ en baño maría por 5 minutos. Luego con pipeta Pasteur de vidrio se recuperó el contenido (pellet) del fondo de los tubos y se depositaron en placas Petri temperadas, que contenía una solución Buffer Fosfato Salino (PBS, Gibco) adicionada con $0.3 \%$ de albúmina sérica bovina (BSA Fracción V, Sigma) y $50 \mu \mathrm{g} / \mathrm{ml}$ de gentamicina (Sigma).

\section{Selección y Maduración de Ovocitos}

Los ovocitos se seleccionaron siguiendo los criterios descritos por Leibfried y First (1979), con cúmulo complejo oophorus (CCO), citoplasma granulado y homogéneo, sin manchas oscuras ni espacios claros ( $\mathrm{Fi}$ gura 1A), visualizados con una lupa estereoscópica (Nikon SMZ445). Los ovocitos se maduraron en placas Petri de 60x 15 (Falcon) con gotas de $50 \mu 1$ del medio de maduración TCM-199 (Sigma), en grupos de 13 por gota durante 24 horas. El medio de maduración fue suplementado con $10 \%$ de suero fetal bovino (SFB) inactivado (Sigma), $50 \mu \mathrm{g} / \mathrm{ml}$ de gentamicina (Sigma), $0.2 \mathrm{mM}$ de piruvato (Sigma), $40 \mathrm{mg} / \mathrm{ml} \mathrm{deFSH}$ (Folltropin), $5 \mu \mathrm{g} / \mathrm{ml}$ de LH (Lutropin) y $1 \mu \mathrm{g} / \mathrm{ml}$ de estradiol $17 \beta$ (Sigma), siendo la incubación a $38^{\circ} \mathrm{C}$ por 24 horas en alta humedad.

\section{Preparación BOEC}

Los cuernos uterinos y oviductos fueron transportados en cajas de poliestireno expandido con hielo seco. En el laboratorio, se separaron los ligamentos y tejido adyacente, con una tijera de iris y pinza de disección estéril, dejando libre el oviducto. Para la extracción de las células oviductales, el con- 
ducto se colocó sobre una placa de Petri, el extremo de la unión útero-tubárica se sujetó con la pinza y con un portaobjeto estéril se ejerció ligera presión de proximal a distal hasta el infundibulum. Se obtuvo un material de aspecto cremoso-amarillento, que fue introducido en un tubo plástico Falcón de $15 \mathrm{ml}$ con $7 \mathrm{ml}$ del medio TCM-199 enriquecido con $1 \%$ de SFB y $50 \mu \mathrm{g} / \mathrm{ml}$ de gentamicina, incubado por $10 \mathrm{~min}$ a $38.5^{\circ} \mathrm{C}$ y lavado por decantación. Este procedimiento se realizó tres veces. Las células oviductales se suspendieron nuevamente en un frasco de cultivo de tejido con $10 \mathrm{ml}$ de TCM-199, enriquecido con $10 \%$ de SFB, $50 \mu \mathrm{g} / \mathrm{ml}$ de gentamicina (Sigma), $0.2 \mathrm{mM}$ de priruvato (Sigma), e incubado con $5.5 \%$ de concentración de $\mathrm{CO}_{2}$ con alta humedad a $38.5^{\circ} \mathrm{C}$ por $48 \mathrm{~h}$. Luego de la incubación, el sobrenadante fue decantado quedando una suspensión que corresponde a las células oviductales. La motilidad de las vesículas era superior al $70 \%$, lo cual fue considerado como un signo de viabilidad y aptas para el cultivo (Ratto et al., 1999).

\section{Preparación de Espermatozoides}

Los espermatozoides provinieron de pajuelas de semen congelado, de un mismo toro con fertilidad comprobada, descongelados en baño maría a $38^{\circ} \mathrm{C}$ por $1 \mathrm{~min}$. El semen se colocó en un microtubo de $1 \mathrm{ml}$, para luego pasar el contenido al tubo de la columna de Percoll, de manera lenta, conservando el orden de la columna. Los gradientes se prepararon según el método Percoll (Parrish et al., 1995). Se centrifugó a $800 \mathrm{G}$ por 20 minutos, se extrajo la columna y el pellet se lavó con $5 \mathrm{ml}$ del medio SP-TALP suplementado con $50 \mu \mathrm{g} / \mathrm{ml}$ gentamicina (Sigma), piruvato $1 \mathrm{mM}$ (Sigma) y $6 \mathrm{mg} / \mathrm{ml}$ de BSA Fracción V (Sigma). La solución fue centrifugada a $400 \mathrm{G}$ durante $6 \mathrm{~min}$, se extrajo el sobrenadante y el pellet se resuspendió en el medio de fertilización, ya sea FERTTALP o TCM-199 modificado, a una concentración final para inseminación de $1 \times 10^{6}$ espermatozoides $/ \mathrm{ml}$. Por último, se depositó gotas de $50 \mu 1$ de la suspensión en placas Petri temperadas a $38.5{ }^{\circ} \mathrm{C}$, con $5.5 \%$ de $\mathrm{CO}_{2}$ y alta humedad, para luego ser cubiertos con parafina líquida.

\section{Fertilización de los Gametos in vitro}

Posterior a la maduración in vitro, los ovocitos fueron asignados al azar a los medios de fertilización FERT-TALP (tratamiento 1) o TCM-199 modificado (tratamiento 2) y co-incubados con los espermatozoides durante $18 \mathrm{~h}$ a $38^{\circ} \mathrm{C}, \mathrm{CO}_{2} 5.5 \%$ y alta humedad.

\section{Cultivo de Embriones in vitro con Célu- las Oviductales}

Finalizada la co-incubación, los ovocitos fecundados se colocaron en microtubos de 1 ml y fueron denudados mediante agitación en vórtex por $3 \mathrm{~min}$. Los cigotos pelados se cultivaron en microgotas con $50 \mu 1$ del medio de cultivo TCM-199, suplementado al 10\% con SBF inactivado (Sigma), $50 \mu \mathrm{g} / \mathrm{ml}$ de gentamicina, $0.2 \mathrm{mM}$ de piruvato (Sigma) y 1 $\mu \mathrm{l}$ de BOEC durante 8 días en la misma condición de humedad, $\mathrm{CO}_{2} \mathrm{y}$ temperatura que el empleado para la fertilización.

Se evaluó la fecundación y desarrollo embrionario in vitro, observando la tasa de segmentación a las 18 y 48 h pos-fecundación, estadio mórula y de blastocisto entre los días 6 y 8 . Los blastocistos expandidos fueron evaluados según los criterios descritos por Lindner y Wright (1983). Se analizaron los resultados mediante la prueba no paramétrica de Chi cuadrado $\left(\mathrm{X}^{2}\right)$ y $\mathrm{Z}$ de proporciones, dentro una tabla de contingencia de $2 \times 2$, utilizando el software SPSS v. 21.

\section{Resultados}

De los 281 ovocitos madurados (Figura 1B), 155 se fertilizaron con el medio FERTTALP y 126 con el medio TCM-199 modificado. La tasa de clivaje de los ovocitos a las $18 \mathrm{~h}$ fue de $25.8 \%(\mathrm{n}=40)$ en el medio FERTTALP, mientras que solo $2.4 \%(\mathrm{n}=3)$ en el medio TCM-199 modificado. Asimismo, a las 

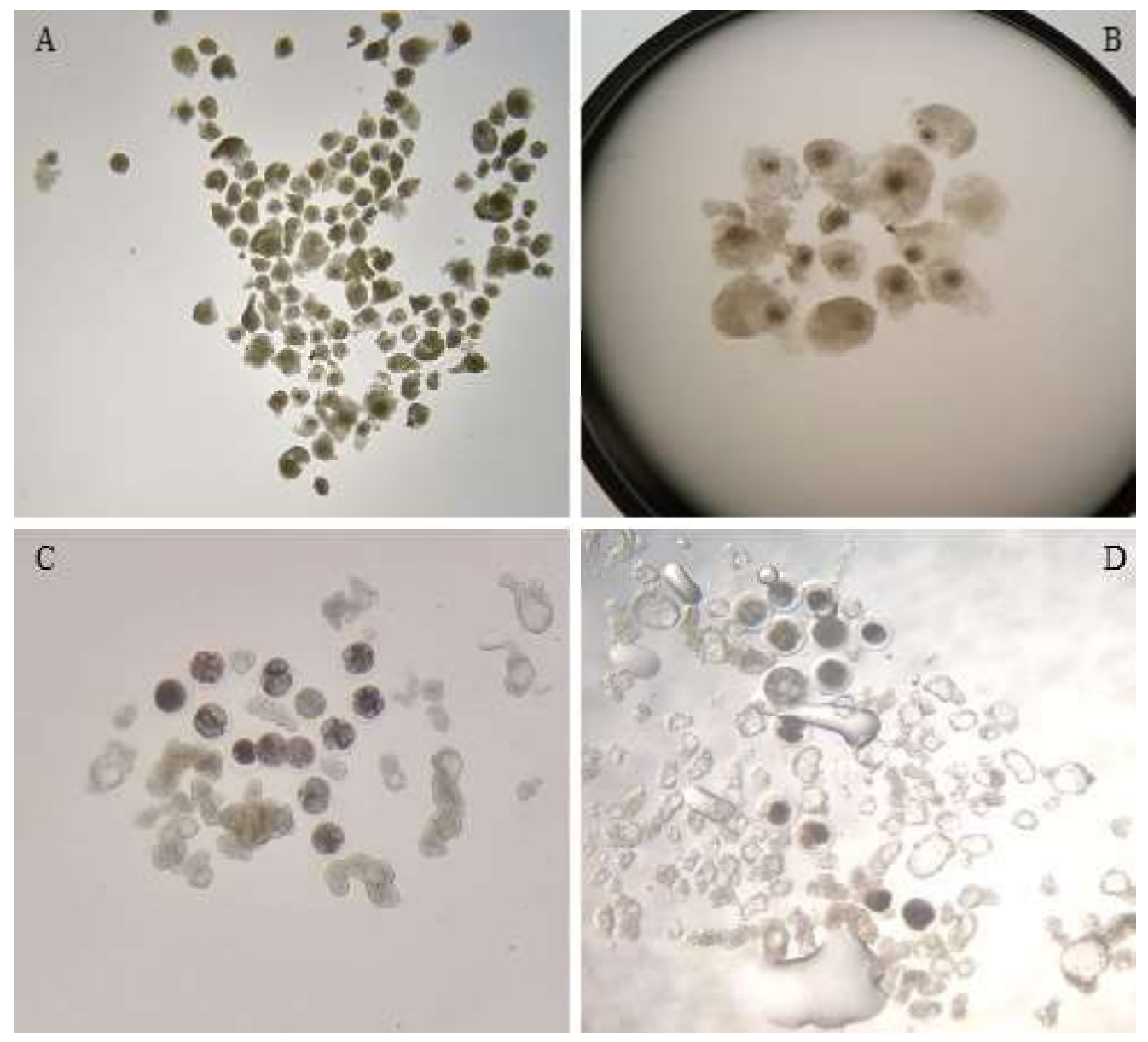

Figura 1. Estadios del cultivo embrionario. A) Ovocitos seleccionados de tipo A y B con cúmulos compactos y citoplasma homogéneo listos para entrar en maduración. B) Ovocitos maduros con cúmulos expandidos. C) embriones de 4 a 8 células co-cultivados en medios BOEC (células epiteliales oviductal bovino). D) Mórulas y blastocistos entre el día 6 a 8

48 h pos-fertilización se obtuvo $87.7 \%$ $(\mathrm{n}=136)$ de clivaje en FERT-TALP, mientras que con el TCM-199 modificado se obtuvo $40.5 \%(n=51)$ (Figura 1C), cuyo porcentaje de embriones con 4-8 células fue de $64.5 \%$ $(\mathrm{n}=100)$ y $26.2 \%(\mathrm{n}=33)$ respectivamente. $\mathrm{Se}$ encontró diferencia significativa $(\mathrm{p}=0.001)$ entre medios en ambas etapas.
En el estadio de mórula y blastocisto se obtuvo $10.3 \%(\mathrm{n}=16)$ y $3.9 \%(\mathrm{n}=6)$ de embriones, respectivamente, con el medio FERTTALP (Figura 1D), en tanto que el resultado fue nulo para los embriones cultivados en el medio TCM-199 modificado ( $<<0.05$; Cuadro 1). 
Cuadro 1. Tasa de producción (\%) de embriones bovinos in vitro, según el estadio de desarrollo y el medio de fertilización

\begin{tabular}{lcc}
\hline \multirow{2}{*}{ Etapa } & \multicolumn{2}{c}{ Medio de fertilización } \\
\cline { 2 - 3 } & FERT-TALP & TCM-199 \\
\hline 4-8 células & $64.5^{\mathrm{a}}$ & $26.2^{\mathrm{b}}$ \\
Mórula & $10.3^{\mathrm{a}}$ & $0^{\mathrm{b}}$ \\
Blastocisto & $3.9^{\mathrm{a}}$ & $0^{\mathrm{b}}$ \\
\hline
\end{tabular}

$a, b$ Letras distintas en una misma fila indican diferencia significativa $(p<0.05)$

\section{Discusión}

Las frecuencias de obtención de embriones en los estadios de mórula y blastocisto fueron superiores con el medio FERT-TALP en comparación con el medio TCM-199 modificado, en el cual no llegaron a desarrollar los embriones. Estos valores resultan bajos en contraste a los reportados por otros in- vestigadores. Berland et al. (2011) obtuvieron $28.4 \%$ de blastocistos usando el medio TALP en fertilización y BOEC en cultivo, en tanto que Ratto et al. (1999) lograron 15.7\% con medio de fertilización BO (Brackett y Oliphant) y BOEC para para cultivo embrionario, y Pahuara, mientras que Noveros (2014) obtuvieron $11.6 \%$ de blastocistos con medio de cultivo KSOMaa y $17.66 \%$ con SOFaa, empleando FERT-TALP en ambos casos para la fertilización. De otra parte, Nedambale et al. (2006) utilizando BO y TCM para la fertilización y SOF (Fluido Oviductal Sintético) para el desarrollo embrionario, lograron una tasa de 16 y $36 \%$ de blastocistos, respectivamente.

Si bien es cierto, el porcentaje de blastocitos obtenidos con FERT-TALP fue similar al obtenido por Fernandez et al. (2007) utilizando el medio de fertilización y maduración HTF (Fluido Oviductal Humano) con 10\% de suero fetal bovino (SFB), los resultados se encuentran relativamente lejos del $10 \%$ mínimo que debería de obtenerse en la maduración de ovocitos in vitro en el estadio de blastocisto (Arav, 2001; Gutiérrez-Adán et al., 2001; Mayes y Sirad, 2001).

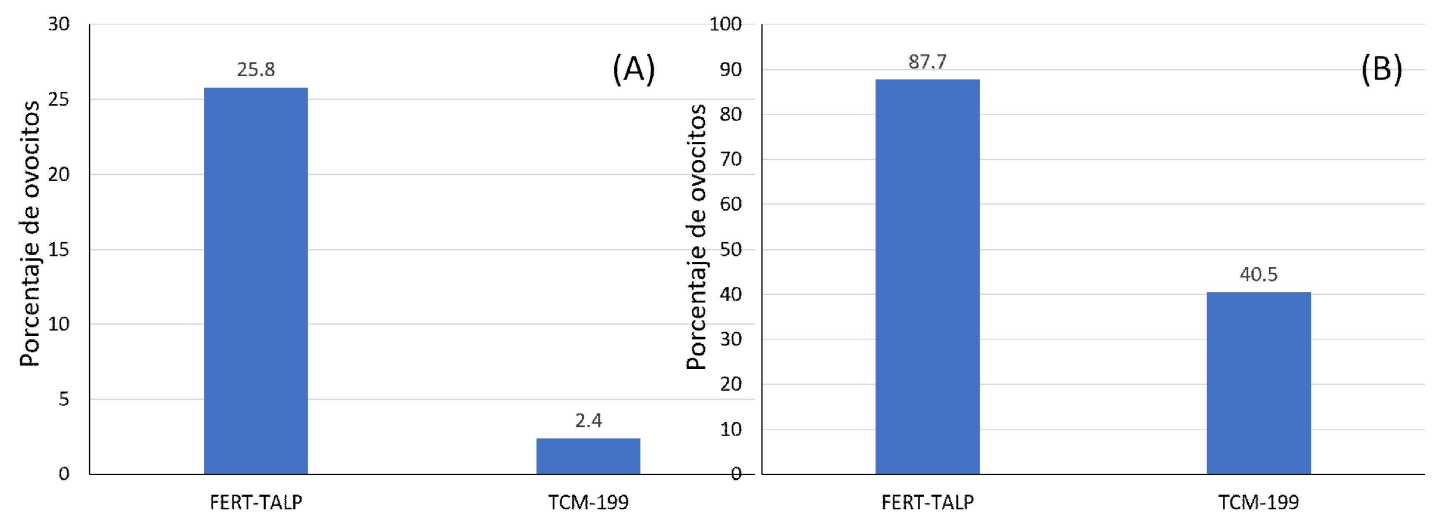

Figura 1. Cultivo de ovocitos en medios de FERT-TALP y TCM-199 modificado. (A) Porcentaje de ovocitos con clivaje a las 18 horas pos-fertilización; (B) Porcentaje de ovocitos con clivaje a las $48 \mathrm{~h}$ pos-fertilización 
Los resultados del estudio, obteniendo $64.5 \%$ de embriones de 4 a 8 células en FERTTALP y $26.6 \%$ con TCM-199 modificado, son similares al reportado por Nedambale et al. (2006), quienes mencionan una tasa de $61 \%$ con TCM-199 y $60 \%$ con medio BO, siendo este último un medio de fertilización convencional empleado en FIV. Asimismo, fue superior en $10.8 \%$ a los resultados obtenidos por Berland et al. (2011) utilizando FERT-TALP y evaluando en el mismo tiempo (53.7\% embriones de 4-8 células).

La baja producción de embriones hasta el estadio blastocisto se pudo deber a una reducción de las competencia de los ovocitos recuperados de ovarios de bovinos criollos o simplemente esté relacionado a las condiciones del co-cultivo para el desarrollo embrionario (BOEC), el cual no siempre logra proporcionar las condiciones óptimas ni las sustancias moduladoras presentes en el oviducto, necesarios para el inicio del desarrollo del embrión bovino (García et al., 2017); bloqueándose de esta manera el desarrollo temprano, aunque no implica la muerte inmediata del embrión, pero sí constituye un punto de inflexión irreversible en el crecimiento futuro (Valleh et al., 2014). En el caso del bovino, el bloqueo en el desarrollo ocurre cuando el embrión pasa de 8 a 16 células (Tarazona et al., 2010), de allí que la tasa de embriones obtenidas de 4 a 8 células fue similar a los reportados por otros autores, pero posterior a esta etapa no se logró el desarrollo deseado.

E1 TCM-199 modificado, empleado como medio de fertilización y cultivado con BOEC, no logró los resultados esperados, a diferencia de Nedambale et al. (2006), quienes obtuvieron una mayor tasa de embriones, usando el mismo medio y el medio SOF para el desarrollo embrionario.

\section{Conclusiones}

- Con el medio FERT TALP se obtuvo un mayor porcentaje de clivaje a las $18 \mathrm{y}$ 48 horas pos- fertilización y embriones bovinos de 4 a 8 células en comparación con el medio TCM-199 modificado.

- Con el medio de fertilización TCM-199 modificado no se logró desarrollar embriones en etapa de mórula ni blastocisto, mientras que con el medio FERT-TALP se obtuvo $10.3 \%$ en estadio de mórula y $3.9 \%$ en blastocisto.

\section{Literatura Citada}

1. Adeoya-Osiguwa SA, Fraser LR. 2002. Capacitation state dependent changes in adenosine receptors and their regulation of adenylyl cyclase/cAMP. Mol Reprod Dev 63: 245-255. doi: $10.1002 / \mathrm{mrd} .90009$

2. Ahuja C, Montiel F, Pérez, P, Gallegos J. 2009. Medio alternativo para la producción in vitro de embriones bovinos. Zootec Trop 27: 277-284.

3. Aitken RJ, Clarkson JS, Fishel S. 1989. Generation of reactive oxygen species, lipid peroxidation and human sperm function. Biol Reprod 41: 183-197. doi: 10.1095/biolreprod41.1.183

4. Arav A. 2001. Transillumination increases oocyte recovery from ovaries collected at slaughter. A new technique report. Theriogenology 55: 1561-1565. doi: 10.1016/s0093-691x(01)00502-7

5. Berland M, Frei M, Peralta O, Ratto M. 2011. Time exposure period of bovine oocytes to sperm in relation to embryo development rate and quality. ISRN Comput Biol 2011: 257627. doi: 10.5402/ 2011/257627 
6. Bilodeau JF, Blanchette S, Gagnon C, Sirard MA. 2001. Thiols prevent $\mathrm{H}_{2} \mathrm{O}_{2}-$ mediated loss of sperm motility in cryopreserved bull semen. Theriogenology 56: 275-286. doi: 10.1016/s0093691x(01)00562-3

7. Enright BP, Lonergan P, Dinnyes $A$, Fair T, Ward FA, Yang X, Boland MP. 2000. Culture of in vitro produced bovine zygotes vs in vivo: implications for early embryo development and quality. Theriogenology 54: 659-673. doi: 10.1016/S0093-691X(00)00381-2

8. Fernandez, A, Diaz T, Muñoz G 2007. In vitro production of bovine embryos. Rev Fac Cs Vet 48: 51-60.

9. Fraser LR, Adeoya-Osiguwa SA. 2001. Fertilization promoting peptide a possible regulator of sperm function in vivo. Vitam Horm 63: 1-28. doi: 10.1016/ s0083-6729(01)63001-2

10. Galli C, Duchi R, Crotti G, Turini P, Ponderato N, Colleoni S, Lagutina I, Lazzari G. 2003. Bovine embryo technologies. Theriogenology 59: 599-616. doi: 10.1016/s0093-691x(02)01243-8

11. García EV, Hamdi M, Barrera AD, Sánchez-Calabuig MJ, GutiérrezAdán A, Rizos D. 2017. Bovine embryo-oviduct interaction in vitro reveals an early cross talk mediated by BMP signalling. Reproduction 153: 631643. doi: 10.1530/REP-16-0654

12. Gordon I. 2003. In nitro fertilization. In: Presley GJ (ed). Laboratory Produc-tion. $2^{\text {nd }}$ ed. UK: CABI Publishing. p 176-219.

13. Gutiérrez-Adán A, Lonergan P, Rizos $D$, Ward FA, Boland MP, Pintado B, de la Fuente J. 2001. Effect of the in vitro culture system on the kinetics of blastocyst development and sex ratio of bovine embryos. Theriogenology 55: 1117-1126. doi: 10.1016/s0093-691x(01)00471-x

14. Irvine DS. 1996. Glutathione as a treatment for male infertility. Rev Reprod 1: 6-12.

15. Leibfried L, First NL. 1979. Characterization of bovine follicular oocytes and their ability to mature in vitro. J Anim
Sci 48: 76-86. doi: 10.2527/jas1979.48176x

16. Lindner GM, Wright RW. 1983. Bovine embryo morphology and evaluation. Theriogenology 20: 407-416. doi: 10.1016/0093-691x(83)90201-7

17. Lonergan P, HG Pedersen, D Rizos, T Greve, PD Thomsen, $T$ Fair, $A$ Evans, MP Boland. 2004. Effect of the postfertilization culture environment on the incidence of chromosome aberrations in bovine blastocysts. Biol Reprod 71: 1096-1100.

18. López A, Olivera M, Ruiz T, Tarazona A. 2007. Efecto del co-cultivo sobre el desarrollo temprano de embriones bovinos producidos in vitro. Rev MVZ Córdoba 12: 1061-1067.

19. Mayes MA, Sirard MA. 2001. The influence of cumulus-oocyte complex morphology and meiotic inhibitors on the kinetics of nuclear maturation in cattle. Theriogenology 55: 911-922. doi: 10.1016/s0093-691x(01)00453-8

20. Nedambale TL, Du F, Xu J, Chaubal $S A$, Dinnyes A, Groen W, Faber D, Dobrinsky JR, Yang X, Tian XC. 2006. Prolonging bovine sperm-oocyte incubation in modified medium 199 improves embryo development rate and the viability of vitrified blastocysts. Theriogenology 66: 1951-1960. doi: 10.1016/j.theriogenology.2006.04.044

21. Pahuara LE, Naveros M. 2014. Producción in vitro de embriones bovinos (Bos taurus) en dos medios de cultivo. Spermova 4: 54-57

22. Parrish JJ, Krogenaes A, SuskoParrish JL. 1995. Effect of bovine sperm separation by either swim-up or Percoll method on success of in vitro fertilization and early embryonic development. Therogenology 44: 859869. doi: 10.1016/0093-691x(95)00271-9

23. Ratto M, Berland M, Wolter M, Matamoros $R$. 1999. Bovine embryo development produced by in vitro fertilization cultured with oviductal cell or conditioned medium and transfer to recipients. Arch Med Vet 31: 89-96. 
24. Rizos D, Ward F, Duffy P, Boland MP, Lonergan P. 2002. Consequences of bovine oocyte maturation, fertilization or early embryo development in vitro versus in vivo: implications for blastocyst yield and blastocyst quality. Mol Reprod Dev 61: 234-248. doi: 10.1002/mrd.1153

25. Tarazona A, Olivera-Angel M, Lenis Y. 2010. Rol de la mitocondria y el estrés oxidativo del desarrollo de embriones bovinos producidos in vitro. Arch Med Vet 42:125-133.
26. Valleh MV, Hyttel P, Rasmussen MA, Strobech L. 2014. Insulin-like growth factor 2: a modulator of anti-apoptosis related genes (HSP70, BCL2-L1) in bovine reimplantation embryos. Theriogenology 82: 942-950. doi: 10.1016/j.theriogenology.2014.07.003

27. Xu KP, Yadav BR, Rorie RW, Plante L, Betteridge KJ, King WA. 1992. Development and viability of bovine embryos derived from oocytes matured and fertilized in vitro and co-cultured with bovine oviducal epithelial cells. J Reprod Fert 94: 33-43. doi: 10.1530/jrf.0.0940033 